\title{
CONFLITOS QUE CERCAM O PROCESSO DE IMPLANTAÇÃO DA RESEX DE TAUÁ-MIRIM - SÃO LUÍS - MA
}

\section{CONFLICTS AROUND THE PROCESS OF IMPLEMENTING THE RESEX OF TAUÁ-MIRIM - SÃO LUÍS - MA}

\author{
Marcelo Alves de Sousa \\ Universidade Federal do Maranhão, São Luís, MA, Brasil \\ marceloprofessor16@gmail.com \\ David Vieira da Silva \\ Universidade Federal do Maranhão, São Luís, MA, Brasil \\ davidvieira0412@hotmail.com
}

\section{Resumo}

O presente trabalho tem como objetivo fazer uma análise dos conflitos que cercam o processo de criação da Reserva Extrativista de Tauá-Mirim, localizada a sudoeste da ilha de São Luís - Estado do Maranhão. Além de observar a burocracia para a implantação da reserva extrativista, pondera-se também sobre as constantemente ameaçadas que as comunidades localizadas na RESEX sofrem pelos grandes projetos de desenvolvimento que procuram se instalar na região. Nessa perspectiva, adverte-se sobre a urgência de sua oficialização, sobretudo, pela necessidade da preservação de seus manguezais, áreas de várzeas e nascentes, assim como da reprodução de várias espécies marinhas e da consideração devida com as comunidades tradicionais que ali vivem. Para isso, utilizou-se como instrumento de coleta de dados entrevistas semiestruturadas com análise através da pesquisa qualitativa.

Palavras-Chave: RESEX. Tauá-Mirim. Conflitos. Comunidades Tradicionais.

\begin{abstract}
This work aims to analyze the conflicts around the creation process of the Tauá-Mirim Extractive Reserve, located southwest of São Luís Island - Maranhão State. In addition to observing the bureaucracy for the implantation of the extractive reserve, the constant threats that the communities located in the RESEX are suffering in reason of the great development projects that are trying to take place in the area are also weight. Hence, it warns the urgency of its approval, mainly due the need to preserve mangroves, floodplain and spring, as well as the reproduction of several marine species and regarding the traditional communities that inhabit over there. For that, semi-structured interviews and analysis through qualitative research were used as a data collection instrument.
\end{abstract}

Keywords: RESEX. Tauá-Mirim. Conflicts. Traditional Communities. 


\section{Introdução}

A legislação que garante as normas para a criação, implantação e gestão das unidades de conservação estão ressaltadas na Lei No 9985/2000, que instituiu o Sistema Nacional de Unidades de Conservação da Natureza - SNUC, da qual classifica a unidade de conservação como sendo um espaço territorial e seus recursos ambientais. Diante disso, é pertinente destacar que esta norma determina que as Reservas Extrativistas devem ser criadas por lei e administradas pelo órgão ambiental apropriado, da qual ressalta que se for lei federal, a responsabilidade de criação fica a cargo do Instituto Chico Mendes (ICMBio); No caso de lei estadual ou municipal, a incumbência para criação é de responsabilidade do órgão ambiental do estado ou município.

O processo de criação da Reserva Extrativista de Tauá-Mirim, localizada a sudoeste da ilha de São Luís - Estado do Maranhão, e que tramita na Justiça Federal, vêm se arrastando durante décadas, ocasionando uma morosidade na oficialização da Reserva Extrativista e gerando os designados conflitos entre as comunidades estabelecidas secularmente com os grandes projetos de desenvolvimento.

Partindo deste cenário atual e levando em consideração as frequentes ameaças pelos grandes projetos de desenvolvimento que procuram se instalar na região, este trabalho teve como objetivo geral analisar os conflitos que cercam o processo de implantação da Resex de Tauá-Mirim - São Luís - MA. Diante disso, para ter uma resposta mais eficaz para esse objetivo geral, traçou-se os seguintes objetivos específicos: Conhecer o conceito de reservas extrativista, sua base legal e a RESEX de Tauá-Mirim; analisar as características e definições de povos e comunidades e ponderar sobre a burocracia no processo de criação da Reserva Extrativista, objeto de estudo da presente pesquisa.

\section{Conceito de Reserva Extrativista, base legal e a RESEX de Tauá-Mirim}

O conceito de Reserva Extrativista se constituiu, de acordo com Moreira (2000), na região amazônica por meio dos seringueiros, sobretudo pela busca da manutenção de seu modo de vida condicionado ao extrativismo de distintos recursos florestais, como o látex das seringueiras nativas e da castanha-do-Brasil. No entendimento de Cunha (2001), a recomendação para criação das Reservas Extrativistas é manifestada nos anos de 1980, tornando-se uma opção sólida de utilização sustentável da terra e dos recursos 
florestais (exceto dos madeiráveis), em virtude do modelo de desenvolvimento implantado na região amazônica.

Diante desse cenário, destaca-se que a concepção de Reserva Extrativista ocorreu em 1985, durante o primeiro Encontro Nacional dos Seringueiros como um importante argumento na tentativa de garantir aos seringueiros a sua permanência em suas terras constantemente ameaçadas pela expansão de grandes pastagens, pela especulação fundiária e pelo desmatamento. Sobre isso, Damasceno (2016, p. 50) destaca que "os maiores inimigos dos seringueiros eram os latifundiários, o agronegócio, as madeireiras e os pecuaristas".

Nessa perspectiva, acentua-se que o conceito de Reserva Extrativista surgiu por meio das populações extrativistas como consequência de uma analogia com as reservas indígenas, levando em consideração que as terras são da União, mas o seu aproveitamento é das comunidades.

O conceito de Reserva Extrativista assume o pressuposto de que a exploração sustentável dos recursos fornecidos pela floresta e demais ecossistemas pode ser a base do desenvolvimento sustentável local, caso esses ecossistemas estejam protegidos de outros usos alternativos e incompatíveis com a sua manutenção. Para que isto seja possível são de diversas áreas os aspectos que devem ser adequadamente ponderados, englobando elementos econômicos, sociais, ecológicos e culturais (MOREIRA, 2000, p. 31).

É extremamente relevante pontuar que a Reserva Extrativista (RESEX) está intimamente ligada ao conceito de área utilizada por populações extrativistas tradicionais, da qual a sua subsistência fundamenta-se tanto no extrativismo como na agricultura de subsistência e na criação de animais de pequeno porte, objetivando além disso, a proteção dos meios de vida, a cultura e uso sustentável dos recursos naturais da unidade. Não obstante, acentua-se que a Reserva é de domínio público, e seu uso é especialmente outorgado às populações extrativistas tradicionais e, de acordo com a segundo a lei, as áreas particulares abrangidas em seus limites precisam ser desapropriadas.

\section{Reserva extrativista: Base Legal}

As Reservas Extrativistas foram introduzidas pela Lei 9.985/00, que criou o Sistema Nacional de Unidades de Conservação da Natureza (SNUC), que foi regulado 
pelo Decreto $n^{0}$ 4.340/02. Nessa perspectiva, o SNUC classifica a unidade de conservação como sendo um espaço territorial e seus recursos ambientais, na qual inclui as "águas jurisdicionais, com características naturais relevantes, legalmente instituído pelo Poder Público, com objetivos de conservação e limites definidos, sob regime especial de administração, ao qual se aplicam garantias adequadas de proteção" (BRASIL, 2000).

Damasceno (2016, p. 58), ressalta que:

Nesta lei estão inclusas as Unidades de Conservação de Uso Sustentável que, ao contrário das Unidades de Conservação de Proteção Integral, permitem populações humanas em seu interior, regidas por um Plano de Manejo. O objetivo básico das Unidades de Uso Sustentável é compatibilizar a conservação da natureza com o uso sustentável de parcela dos seus recursos naturais. Nessa categoria, juntamente com outros seis tipos, estão localizadas as Reservas Extrativistas.

Desta maneira, é pertinente destacar que o SNUC é constituído pelo conjunto das unidades de conservação correspondente as esferas federais, estaduais e municipais, sendo, contudo, constituído por 12 categorias de UC, tendo como principal objetivo a diferenciação das formas de proteção, assim como dos usos permitidos. Todavia, o órgão destaca ainda que as Unidades de Conservação são aquelas que necessitam de maiores cuidados por conta da sua fragilidade e particularidades, devendo ser utilizadas atentando para tanto seu aspecto sustentável como para sua conservação ao mesmo tempo (BRASIL, 2011).

Diante desse cenário, cabe destacar que a Reserva Extrativista é administrada por um Conselho Deliberativo, presidido pelo órgão responsável por sua gestão e estabelecido levando em conta a representação de órgãos públicos, organizações da sociedade civil, bem como das populações tradicionais residentes na área. Observa-se que existem ainda três tipos de Reservas, como a Reserva de Fauna (RFAU), Reserva de Desenvolvimento Sustentável (RDS) e Reserva Particular do Patrimônio Natural (RPPN).

Quanto a Reserva de Fauna (RFAU), nota-se que é um tipo de reserva que é composta por uma área natural com populações animais de espécies nativas, terrestres ou aquáticas, residentes ou migratórias. No que tange a Reserva de Desenvolvimento Sustentável (RDS), verifica-se que é uma área de característica natural, tendo como um 
dos principais objetivos abrigar populações tradicionais. Não obstante, acentua-se ainda que nesse tipo de reserva tem em sua essência os sistemas sustentáveis de exploração dos recursos naturais, assim como suas populações extrativistas simbolizam outros grupos sociais envolvidos na classe de tradicionais com a possibilidade de serem reconhecidas pelos produtos que extraem e vendem no mercado, destacando-se os seringueiros, castanheiros, babaçueiros e pescadores (LITTLE, 2004).

Por fim, têm-se a Reserva Particular do Patrimônio Natural (RPPN), que tem como sua principal característica a implementação em uma área privada. Desta forma, as RPPN são criadas por iniciativa do proprietário, com a finalidade de conservar a diversidade biológica. Nessa perspectiva, cabe destacar ainda que nesse tipo de unidade de conservação as visitações são permitidas somente para fins de pesquisa científica e atrativos turísticos, recreativos e educacionais. Destaca-se, contudo, que nessas Reservas são proibidas a exploração de recursos minerais e a caça amadora ou profissional, e a exploração comercial de recursos madeireiros só será admitida em bases sustentáveis e em situações especiais e complementares às demais atividades desenvolvidas na RESEX.

\section{Reserva Extrativista de Tauá-Mirim}

Tauá-Mirim fica localizada na Zona Rural do município de São Luís (MA), na costa Sudoeste da Ilha do Maranhão, igualmente denominada de Ilha de Upaon-Açu, na região correspondente ao Estreito dos Coqueiros (ou Rio Coqueiro) e a Baía de São Marcos. Segundo Damasceno (2016), Tauá-Mirim é a denominação utilizada para uma Reserva Extrativista (RESEX) que aguarda pelo processo de oficialização pelo Estado brasileiro, desde o ano de 2003, quando foi dado um pontapé inicial com um abaixoassinado pelas comunidades para dar início ao processo de criação da Reserva Extrativista.

Desta maneira, é relevante observar que a área indicada para a RESEX de TauáMirim compreende diversos povoados da Ilha (Figura 01), como uma porção correspondente a Praia de Parnauaçu, na comunidade do Cajueiro, assim como a comunidade do Limoeiro, Porto Grande, Rio dos Cachorros, Taim e parte da Vila Maranhão. Não obstante, a Ilha de Tauá-Mirim inclui ainda os povoados Amapá, Embaubal, Jacamim, Portinho, Ilha Pequena e Tauá-Mirim, bem como espelho d'água 
na Baia de São Marcos bastante amplo, totalizando 16.663,55 hectares e perímetro de $71,21 \mathrm{~km}$.

Mapa 01: Área proposta para a criação da Resex de Tauá-Mirim

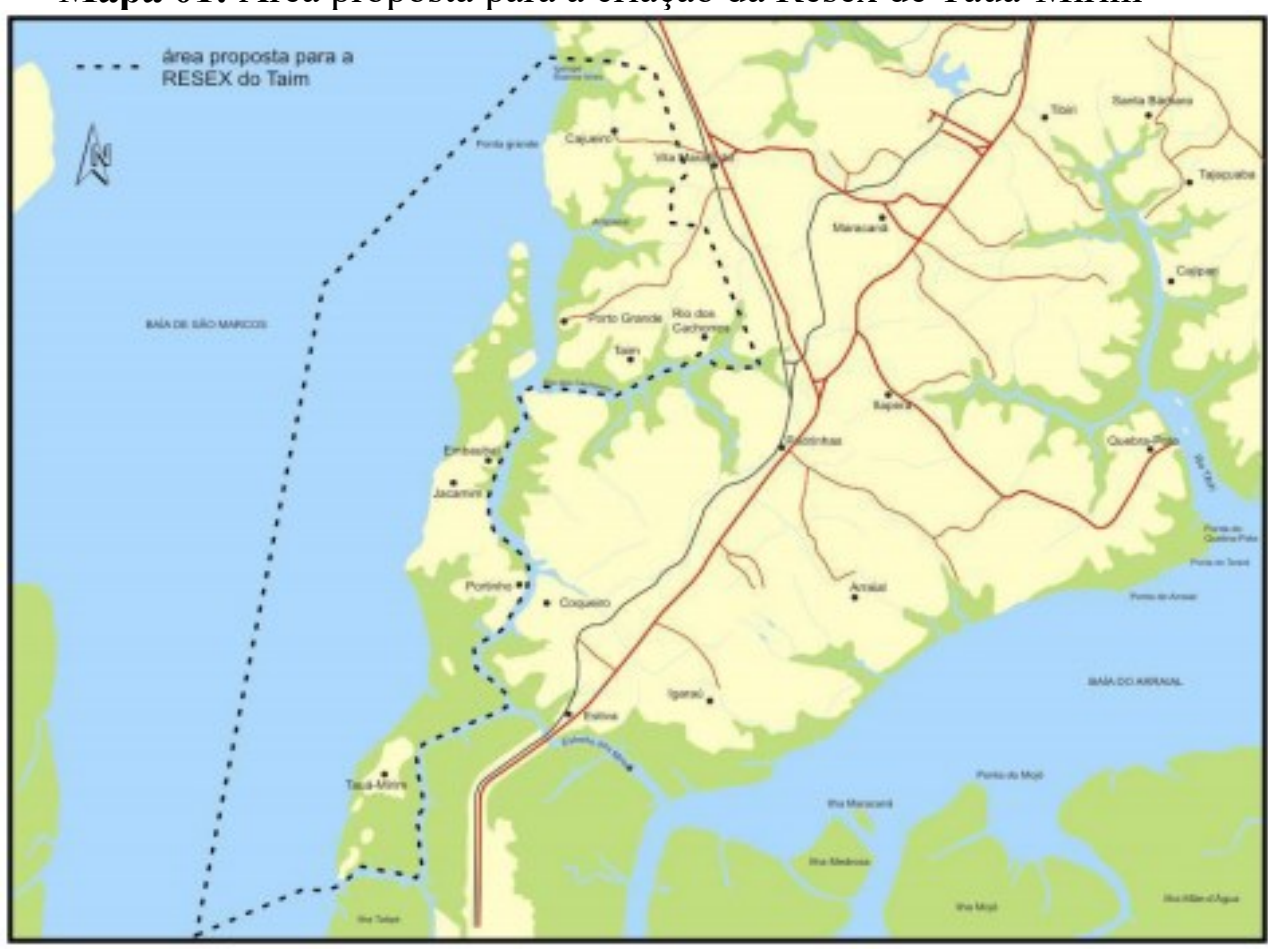

Fonte: Laudo Socioeconômico e Biológico da Reserva Extrativista do Taim (IBAMA, 2007).

É pertinente constatar que as orientações para a criação das Resex são apresentadas com a intenção de garantir tanto a conservação da biodiversidade quanto da sustentabilidade ambiental, do mesmo modo promove a participação ativa das populações tradicionais, para que sejam reconhecidos e valorizados os seus saberes, seus territórios e formas de organização social, como o que ocorre com o território que abrange a área proposta para a RESEX de Tauá-Mirim, que de acordo com Sant'Ana Júnior et al. (2009, p. 25), possuem ainda:

[...] vasta extensão de manguezais e a existência de um modo de vida ancestralmente construído, com baixos índices de agressão ao meio, permite configurar a região como um território ocupado por populações tradicionais que utilizam e se apropriam de espaços e recursos naturais a partir de seus conhecimentos tradicionais e suas relações de reciprocidade e de parentesco. Esses são os principais argumentos para justificar a criação da RESEX de Tauá-Mirim. 
Logo, destaca-se que nessa área além de possuir uma intensa presença de manguezais, várzeas e nascentes e de reprodução de várias espécies marinhas, há também povos e comunidades tradicionais que possuem um modo de vida bastante peculiar nos seus limites aliados às condições ecológicas com o predomínio da atividade agrícola, pesca e criação de pequenos animais. Entretanto, nota-se que com a lentidão no andamento do processo de criação da reserva extrativista, se verifica que há igualmente uma preocupação com quanto ao futuro das pessoas que se estabeleceram na região ao longo de décadas, uma gente que nasceu pertinho do mar e aprendeu a viver da natureza e defende o ambiente para as gerações futuras.

\section{Povos e comunidades tradicionais: características e definição}

Para conhecer o universo que cercam "povos e comunidades tradicionais", contextualiza-se inicialmente na presente pesquisa sobre um breve conceito de povos, que pode ser entendido levando em consideração os aspectos políticos, jurídicos e sociológicos. Entretanto, destaca-se que a modernidade do conceito é consagrada nos estudos de alguns autores, da qual muitos se baseiam nas considerações atinentes à Revolução francesa. Desta maneira, observa-se que o conceito apresentou diversas conotações ao longo da história desde a antiguidade, em que cada momento lhe conferiu um determinado papel.

Nesse contexto, denomina-se povos às pessoas que em conjunto compõem uma nação, uma comunidade de menor escala ou espaço onde ocorrem os principais movimentos e que refletem com o tempo. Ao se fazer uma abordagem dos estudos de povos tradicionais no Brasil, faz necessário dialogar com os estudos do autor Paul E. Little, da qual argumenta que:

No caso dos povos tradicionais do Brasil, uma grande semelhança pode ser detectada nas distintas formas de propriedade social, que as afastam da razão instrumental hegemônica com seu regime de propriedade baseado na dicotomia entre o privado e o público. Todavia, a razão histórica a elas subjacente incorpora alguns elementos que muitas vezes são considerados como públicos - isto é, bens coletivos -, mas que não são tutelados pelo Estado; ou seja, essa razão histórica introduz coletividades que funcionam em um nível inferior no plano do Estado-nação. No entanto, incorpora elementos comumente considerados como privados, no caso de bens 
pertencentes a um grupo específico de pessoas, mas que existem fora do âmbito do mercado (LITTLE, 2004, p. 259).

Conforme a Política Nacional de Desenvolvimento Sustentável dos Povos e Comunidades Tradicionais (PNPCT), Povos e Comunidades Tradicionais (PCTs) são definidos como "grupos culturalmente diferenciados e que se reconhecem como tais, que possuem formas próprias de organização social, que ocupam e usam territórios e recursos naturais como condição para sua reprodução cultural, social, religiosa, ancestral e econômica (...)" (BRASIL, 2007). Desta maneira, cabe ressaltar ainda que são analisados como povos e comunidades tradicionais no Brasil os povos indígenas, as comunidades remanescentes de quilombos, os pescadores artesanais, os ribeirinhos, os povos ciganos, os povos de terreiros, dentre outros.

Os povos e comunidades tradicionais são grupos culturalmente diferenciados,
que possuem condições sociais, culturais e econômicas próprias, mantendo
relações específicas com o território e com o meio ambiente no qual estão
inseridos. Respeitam também o princípio da sustentabilidade, buscando a
sobrevivência das gerações presentes sob os aspectos físicos, culturais e
econômicos, bem como assegurando as mesmas possibilidades para as
próximas gerações (MPMG, 2014, p. 12).

No Decreto Lei $n^{\circ}$ 6.040/2007, o Governo Federal institui a Política Nacional de Desenvolvimento Sustentável dos Povos e Comunidades Tradicionais - PNPCT, que têm como um dos seus principais objetivos, "coordenar a implementação da Política Nacional para o Desenvolvimento Sustentável dos Povos e Comunidades Tradicionais". De acordo com este decreto, em seu inciso primeiro, Povos e Comunidades Tradicionais são grupos com aspectos culturais bem distintos, tendo um reconhecimento desses aspectos como essenciais. Contudo, tem-se ainda a Instrução Normativa ICMBio n ${ }^{\circ} 03$, de 18/9/2007 - que tem como objetivo principal disciplinar as diretrizes, normas e procedimentos para a criação de Unidade de Conservação Federal das categorias Reserva Extrativista e Reserva de Desenvolvimento Sustentável.

Não obstante, há um entendimento de que as comunidades tradicionais possuem suas próprias formas de organização social, no que se "ocupam e usam territórios e recursos naturais como condição para sua reprodução cultural, social, religiosa, ancestral e econômica, utilizando conhecimentos, inovações e práticas gerados e transmitidos pela tradição" (BRASIL, 2007). Além disso, praticam a pesca, coleta de mariscos, agricultura familiar, mantendo uma relação sustentável com os recursos 
ambientais, mantêm suas próprias formas de organização comunitária, ocupam ancestralmente a área, constituindo um modo de vida e uma cultura próprio (SANT’ANA JÚNIOR et al. 2009).

Os povos e comunidades tradicionais são titulares de forma integral e gratuita do direito fundamental à assistência jurídica que deve ser adotada de forma coletiva, sempre que existir necessidade de afirmação, reconhecimento, proteção e defesa que compreendem seus direitos étnicos e territoriais. Sendo assim, a garantia do ingresso à Justiça compreende igualmente o direito de fazer parte de todos os processos que lhes estejam intimamente ligados, tanto de forma direta ou indireta, como componentes desses povos e comunidades tradicionais, ou por meio de suas organizações representativas. (MPMG, 2014).

Nesse contexto, as PCTs são especialmente denominadas de grupos que possuem uma cultura peculiar, possuindo ainda condições sociais e econômicas favoráveis para a manutenção de suas relações com o território e com o meio ambiente do qual fazem parte, reivindicando seus espaços ocupados durante séculos, seja essa ocupação ou de forma permanente ou temporária, preservando seus modos de ser, fazer e viver extremamente característicos. São povos que ocupam ou reivindicam seus territórios ocupados de forma permanente ou temporária de acordo com a tradição, em que seus membros possuem modos de ser, fazer e viver diferentes dos da sociedade em geral, ao passo que se reconheçam como portadores de identidades e direitos próprios.

\section{Materiais e métodos}

Nesse contexto de estudo, tem-se como metodologia a pesquisa qualitativa, da qual foram realizadas junto a interlocutores selecionados entrevistas semiestruturadas com uso de gravador, em que se fez uma análise de material descritivo com a observação dos participantes. Desta maneira, destaca-se que a escolha desses respondentes se deu pelo papel privilegiado de terem nascido e ainda permanecem na comunidade e, por conta disso, vivenciam a demora na oficialização da Reserva Extrativista, problemática esta que está ocasionado conflitos entre as comunidades estabelecidas secularmente com os grandes projetos de desenvolvimento.

Foram adotados ainda outros procedimentos metodológicos para se ter maior compreensão e visualização dos conceitos atinentes ao tema, como o uso da pesquisa 
bibliográfica para nivelamento teórico; Acompanhamento e registro do noticiário sobre conflitos socioambientais veiculado na imprensa nacional e local. Além disso, fez-se visitas de campo nas áreas com conflitos socioambientais, com observação do cotidiano e de eventos e, por fim, a presente pesquisa se preocupou com o acompanhamento e observação de audiências públicas, reuniões, assembleias e outros momentos de realização de debates públicos envolvendo os casos empíricos selecionados, cuja metodologias aqui apresentadas foram fundamentais para se chegar a uma concepção sobre os conflitos que cercam o processo de criação da Reserva Extrativista de TauáMirim, localizada a sudoeste da ilha de São Luís -Maranhão.

\section{Resultados e discussões}

De acordo com Almeida e Rezende (2013), há uma grande quantidade de casos de expulsão de moradores de territórios tradicionais por conta da declaração de seus territórios como Unidades de Conservação de Uso Indireto, compreendendo desde governo do presidente Jânio Quadros até o fim da ditadura militar. Não obstante, os autores destacam ainda que esses territórios são resididos por comunidades tradicionais que se deparam sob pressão direta ou do ICMBio ou de ações judiciais em nível estadual do Ministério Público Federal (MPF).

No que diz respeito a Reserva Extrativista de Tauá-Mirim, desde o final da década de 1970 e início da década de 1980, presencia-se a instalação e funcionamento em suas adjacências da Estrada de Ferro Carajás e seus terminais, bem como do Complexo Portuário de São Luís e de grandes indústrias minero-metalúrgicas, como os que compreendem o consórcio ALCOA/ALUMAR, a Vale e subsidiárias administrativas de indústrias petrolíferas, como a PETROBRÁS. Nessa perspectiva, compreende-se que com a instalação destes empreendimentos contribuiu para um forçoso deslocamento de várias comunidades, além de seu funcionamento ocasionar uma série de problemas ambientais na região, começando, sobretudo, por vastas áreas desmatadas.

$\mathrm{Na}$ comunidade do Cajueiro, entrevistamos os representantes da Associação de Moradores local, Senhor Davi e Senhor Clóvis e, na Comunidade do Taim, o Senhor Alberto Cantanhede Lopes, da qual esta escolha teve como critério o fato de terem nascido e ainda permanecem na comunidade e, por conta disso, vivenciam a demora na 
oficialização da Reserva Extrativista. Nessa perspectiva, entrevistamos primeiramente o Senhor Davi (Presidente da associação de Moradores), que ao ser perguntado se a comunidade já tinha sofrido alguma intervenção por parte de algum empreendimento, destacou que a comunidade do Cajueiro sofre ataques constantemente de empresas que buscam fazer a ocupação daquela região e, que em 2014, começaram os ataques; mas foi no dia 18 de dezembro do mesmo ano que essas ofensivas tomaram uma proporção ainda maior, configurando-se como extremante grave com a derrubada de dezesseis casas.

De acordo com o senhor Clóvis, a comunidade possui registro no Instituto de Colonização e Terras do Maranhão (ITERMA) desde 1998; porém, segundo ele, uma empresa apareceu com um documento falsificado afirmando que ela possuía o direito sobre aquela localidade. No entanto, tornar esse lugar uma reserva extrativista é um sonho antigo dos moradores da região, sobretudo, por conta do processo de criação da reserva que se alastra há mais de dez anos.

A área proposta para a reserva compreende outros nove vilarejos, como a comunidade do Cajueiro, Limoeiro, Porto Grande, Amapá, Embaubal, Jacamim, Portinho e Tauá, contendo, contudo, uma unidade de conservação com quase 17 mil hectares. Nessa perspectiva, as unidades de conservação têm, em todo seu contexto histórico, uma série de conflitos que tem como um de seus principais objetivos, a expulsão de moradores tradicionais de seus territórios (Territórios Quilombolas, Terras Indígenas e Reservas Extrativistas).

O processo de instalação da Reserva cumpriu as fases, legalmente previstas, de elaboração de laudos biológicos e socioeconômicos e de consulta pública à população, visando verificar se a demanda pela Reserva corresponde efetivamente à vontade dos agentes sociais envolvidos. No momento em que estamos encerrando este livro, depois de ter passado pelo exame por parte do Ministério do Meio Ambiente, foi encaminhado para a Casa Civil da Presidência da República e aguarda a sanção do Presidente da República (SANT'ANA JÚNIOR et al. 2009, p.28).

Na Comunidade do Taim, entrevistamos o Senhor Alberto Cantanhede Lopes, conhecido por "Beto do Taim”, ex-presidente da Associação de Moradores, é pescador e liderança comunitária, no qual nos relatou os avanços que a comunidade já tinha alcançado e alguns problemas que ela ainda enfrentava. De acordo com o morador, "a 
ausência do documento da Terra, o não investimento em equipamentos públicos, como escolas, posto de saúde não são meros desleixos ou falta de planejamento, é um planejamento pra ser assim”. Desta forma, observa-se que o próprio poder público municipal está se ausentando das responsabilidades junto à população com o intuito de contribuir com o afastamento dos moradores da região.

[...] o início da judicialização do conflito em torno da RESEX não marca seu início de fato, mas o momento a partir do qual esse se torna público, ou se torna um conflito visível no meio jurídico. No Ministério Público Federal (MPF) foram instaurados dois (02) Inquéritos Civis Público (ICP) para investigar denúncias envolvendo a criação da Reserva Extrativista de Tauá-Mirim e ameaças à segurança dos povos e comunidades tradicionais que habitam a área (DAMASCENO, 2016, p. 25).

Um outro ponto pertinente diz respeito a aceitação por parte das comunidades quanto aos seus direitos de uso e ocupação do território. Para Beto "Os níveis de compreensão também são diferentes dentro das comunidades". O ex-presidente da Associação de Moradores destacou ainda que "de onde sai o processo que é o Taim, a gente tem mais pessoas envolvidas, tem mais pessoas com nível de compreensão maior" e cita as comunidades do Rio dos Cachorros e do Cajueiro que se preocupam com esse envolvimento.

Em parte da área requerida para a criação da Reserva Extrativista de TauáMirim, desde 2001, ocorreu a tentativa de instalação de um polo siderúrgico, abrangendo uma vasta transação que teve como parte diretamente, os poderes executivos federal, estadual e municipal, que ajustariam a infraestrutura necessária, contendo a permissão da área para as instalações físicas e de estímulos fisscais, correspondendo ainda a regularização dos aspectos legais que viabilizassem sua instalação (SANT'ANA JÚNIOR et al. 2009).

No entanto, o morador ressalta que há comunidades que por influência de empresas que atuam na região, acham que a criação da unidade é prejudicial e "não se envolve com a criação da unidade", como é o caso da comunidade de Porto Grande, sobretudo por conta de empresas ligadas a Alcoa e Vale que possuem um grande número de moradores que desenvolvem atividade laboral nessas empresas, ao passo que se sentem ameaçados com um possível desligamento das empresas caso venham à tona possíveis manifestações à favor da implantação da RESEX. 
Conforme levantamento e acompanhamento de registro do noticiário sobre conflitos socioambientais veiculado na imprensa nacional e local, observa-se que desde junho de 2014, a empresa WPR São Luís Gestão de Portos e Terminais Ltda., por intercessão da consultoria ambiental Urbaniza Engenharia, se manifesta como proprietária empreendedora da Comunidade Cajueiro (região que está localizada dentro área proposta para a RESEX) gerando graves atos de violência, fraude $\mathrm{e}$ intimidação contra as comunidades do entorno e moradores tradicionais da área. Entretanto, apesar das comunidades possuírem os direitos possessórios legítimos e conferidos por título do Estado, continuam sendo tratadas como invasoras. No que lhe diz respeito, o licenciamento ambiental do terminal portuário, que era efetivado pela Secretaria de Estado de Meio Ambiente e Recursos Naturais do Maranhão (SEMA), evidencia graves indicativos de ilegitimidade, desconfiança, abuso de poder, falta de transparência, ocultação e inconsistência de estudos socioambientais.

Portanto, destaca-se que essas ações da empresa, somados aos interesses do governo do Estado do Maranhão, são objetos de ações civis públicas e inquéritos civis, tendo culminado, recentemente, na suspensão do licenciamento ambiental. Entretanto, os problemas no cotidiano dessas comunidades continuam, ao passo que as mesmas constantes ameaças se ampliaram por comunidades do entorno, ocasionando intimidação, indícios de grilagem, violência física, destruição de propriedades, e inúmeros outras ações ilegais em desfavor de centenas de famílias que ocupam essas áreas por décadas e ancestralmente.

\section{Considerações finais}

São muitos os conflitos que cercam o processo de criação da Reserva Extrativista de Tauá-Mirim, localizada a sudoeste da ilha de São Luís - Estado do Maranhão, lesando não apenas o meio ambiente e a zona de amortecimento da Unidade de Conservação; mas igualmente concorrendo de forma direta pelo uso do território, deslocamento compulsoriamente várias famílias pertencentes aos povoados da RESEX.

Verificou-se ainda que o processo vem se arrastando durante décadas, ocasionando uma demora na oficialização da Reserva Extrativista e gerando os designados conflitos entre as comunidades estabelecidas secularmente com os grandes 
projetos de desenvolvimento, sobretudo, o da instalação de um Polo Siderúrgico na Ilha, que de forma evidente passou por uma elaboração de oficinas prévias às audiências públicas, em que estas últimas foram feitas sem divulgação adequada e com boicote por parte das instituições que representam o Estado.

Além dos empreendimentos de maiores portes, a área do Distrito Industrial e seu entorno sofrerem constantemente com transformações relacionadas com as atividades das quais as ocorrências influenciam expressivamente no meio, alterando os modos de vida locais de forma direta. Não obstante, observa-se ainda que o próprio poder público municipal se ausenta das responsabilidades junto à população, tornando-se o responsável por enquadrar as consequências dos projetos à realidade local e contribuindo com o afastamento dos moradores da região.

Nota-se que com a lentidão no andamento do processo de criação da reserva extrativista, se verifica que há igualmente uma preocupação quanto ao futuro das pessoas que se estabeleceram na região ao longo de décadas, um povo que nasceu pertinho do mar e aprendeu a viver da natureza e defende o ambiente para as gerações futuras. Destaca-se que nessa área além de possuir uma intensa presença de manguezais, várzeas e nascentes e de reprodução de várias espécies marinhas, há também povos e comunidades tradicionais que possuem um modo de vida bastante peculiar nos seus limites aliados às condições ecológicas com o predomínio da atividade agrícola, pesca e criação de pequenos animais.

Logo, é importante salientar que a experiência que os moradores dessas comunidades adquiriram durante décadas convivendo nessa região não deve ser analisada unicamente como uma relação deles com os empreendimentos e os impactos socioambientais ocasionados por suas ações, mas sim, perceber que em sua luta pela defesa do território, os habitantes das referidas comunidades conseguem formar um especial discurso pronunciado em defesa do território e do modo de vida peculiar de cada um, concretizando desta maneira, uma supervalorização da sua identidade como moradores pertencentes àquelas comunidades. 


\section{Referências}

ALMEIDA, Mauro W. Barbosa de; REZENDE, Roberto Sanches. Uma nota sobre comunidades tradicionais e unidades de conservação. Ruris, Campinas, vol. 7, n. 2, p.185-196, set. 2013.

BRASIL, LEI $n^{\circ}$ 9.985, de 18 de Julho de 2000. Regulamenta o art. 225, §1o, incisos I, II, III e VII da Constituição Federal, institui o Sistema Nacional de Unidades de Conservação da Natureza. Brasília: Diário Oficial da República Federativa do Brasil. Disponível em $<$ http://www.planalto.gov.br/ccivil_03/LEIS/L9985.htm>. Acesso em 20 de novembro de 2017.

Decreto $n^{\circ} 6040$, de 7 de fevereiro de 2007. Institui a Política Nacional de Desenvolvimento Sustentável dos Povos e Comunidades Tradicionais. Brasília: Diário Oficial da República Federativa do Brasil. Disponível em: < http://www.planalto.gov.br/ccivil 03/ ato2007-2010/2007/decreto/d6040.htm>. Acessado em: 25 de novembro de 2017.

Ministério do Meio Ambiente. SNUC - Sistema Nacional de Unidades de Conservação da Natureza: Lei $n^{\circ}$ 9.985, de 18 de julho de 2000; Decreto ${ }^{\circ}$ 4.340, de 22 de agosto de 2002; Decreto $n^{\circ}$ 5.746, de 5 de abril de 2006. Plano Estratégico Nacional de Áreas Protegidas: Decreto n ${ }^{\circ}$ 5.758, de 13 de abril de 2006. Brasília: MMA, 2011. 76 p.

CUNHA, Lúcia Helena de Oliveira. Reservas extrativistas: uma alternativa de produção e conservação da biodiversidade. Disponível em:

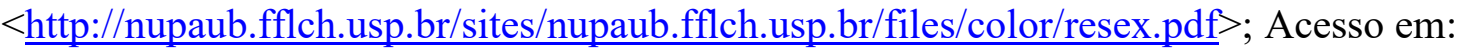
10 de Outubro de 2017.

DAMASCENO, Elena Steinhorst. A Resex de Tauá-Mirim e seus rizomas: um trabalho de construção coletiva e etnografia do processo. 2016. 232 f. Tese (Programa de PósGraduação em Políticas Públicas) - Universidade Federal do Maranhão, São Luís, 2016.

IBAMA/CNPT - MA. Laudo Sócio-Econômico e Biológico para a Criação da Reserva Extratista do Taim. São Luís, 2007, Mimeo.

LITTLE, Paul Elliot. Territórios sociais e povos tradicionais no Brasil: por uma antropologia da territorialidade. Brasília: UnB, 2004, (Série Antropologia, n. 322). $32 \mathrm{p}$.

MOREIRA, André de Castro Cotti. Reserva Extrativista do Bairro Mandira - a viabilidade de uma incerteza / André de Castro Cotti Moreira. São Paulo: Annablume, FAPESP, 2000. 284p.

MPMG, MINISTÉRIO PÚBLICO DO ESTADO DE MINAS GERAIS: COORDENADORIA DE INCLUSÃO E MOBILIZAÇÃO SOCIAIS (CIMOS)

CARTILHA: Direitos dos Povos e Comunidades Tradicionais: Belo Horizonte, MG 2014, 40 p. Disponível em: 
$<$ http//www.mpmg.mp.br/comunicacao/producaoeditorial/direitos-dos-povosecomunidadestradicionais.htm>. Acesso em: 20 de setembro de 2017.

MOREIRA, André de Castro Cotti. Reserva Extrativista do Bairro Miranda - a viabilidade de uma incerteza / André de Castro Cotti Moreira - São Paulo: Annablume, FAPESP, 2000.

SANT 'ANA JÚNIOR, Horácio Antunes et al. Ecos dos conflitos socioambientais: a Resex de Tauá-Mirim / Organizadores: Horácio Antunes de Sant Ana Júnior, Madian de Jesus F. Pereira, Elio de Jesus P. Alves, Carla Regina A. Pereira. - São Luís: Edufma, 2009. 322 p. 